\title{
Comparison between Nickel and Chromium Levels in Saliva of Children Having Space Maintainers versus Stainless Steel Crowns (Comparative Study)
}

\author{
Ahmed Abd-Elrahman Mohamed ${ }^{1}$, Amel Mahmoud Ahmed ${ }^{2}$, Tasneem Tarek Mahmoud ${ }^{3}$ \\ ${ }^{1}$ Professor of Pediatric Dentistry and Dental Public Health, Alexandria University, Faculty of Dentistry, Alex, Egypt \\ ${ }^{2}$ Lecturer of Pediatric Dentistry, Alexandria University, Faculty of Dentistry, Alex, Egypt \\ ${ }^{3}$ BDS, MS, Alexandria University, Faculty of Dentistry, Alex, Egypt
}

\begin{abstract}
Aim: The purpose of this study is to investigate and compare the salivary level of nickel and chromium in the children having lingual arch space maintainer appliances versus those having stainless steel crowns (SSC). Subjects: A total of 34 patients were selected from those referred to the clinic of pediatric dentistry department and allocated into two groups 17 patients each. The first group will be those in need of lingual arch space maintainer without any other metallic restorations. The second group will be patients in need of two stainless steel crowns restoration also with no other metallic fillings or appliances. Methods: The salivary samples will be taken from the patients in four stages: before appliances or crowns cementation then after 1 month, 3 months, and 6 months following cementation. The salivary samples will be collected in a plastic tube and will be stored in the freezer before analysis. The samples will be then transferred to the central laboratory in faculty of science Alexandria University, and the levels of metals will be determined by atomic absorption spectrophotometer with an auto sampler. Each sample will be analyzed three times, and the average will be reported to detect accurately the elements levels. Results: There was a significant increase in the salivary levels of nickel and chromium elements in both groups after cementation of space maintainer appliances or SSC. The amount of released nickel and chromium were significantly higher in group I when compared to group II. Conclusion: The amount of salivary nickel and chromium released after lingual arch space maintainer appliances were more than those after SSC. Also the maximum amounts of released nickel and chromium were much lower than the dietary intake and were not capable of causing any toxicity.
\end{abstract}

Keywords: biodegradation, salivary metals, lingual arch space maintainer, SSC

\section{Introduction}

In recent years, there has been an increasing ecological and global public health concern associated with environmental contamination by metallic alloys [1].A large variety of these metallic alloys are routinely used in dentistry. In 1929, stainless steel was used for the first time to replace gold. Stainless steel containing about 8-12\% nickel (Ni), 17- 22\% chromium $(\mathrm{Cr})$, and various proportions of manganese, copper, titanium, and iron $[2,3]$.

The most significant human exposure to nickel and chromium occurs through the diet. The average dietary intake for these metals has been estimated to be 200-300 $\mathrm{mg} / \mathrm{d}$ for nickel and 50-200 mg/d for chromium [4].

Nickel and chromium can release from the bands and orthodontic wires during treatment and can lead to reduction of the appliance strength as well as adverse biologic hazards such as allergic reaction to nickel [4,5]. These reactions include various clinical manifestation such as inflammation and redness of the gingiva or lips, angioedema, eczema or burning sensation[6-8].Other allergic reactions may also occur from nickel and chromium exposure such as labial desquamation, erythema multiforme or stomatitis with mild to sever erythema of the tongue and angular chelitis $[6,7]$.

In addition, significant carcinogenic and mutagenic potentials have been demonstrated for compound containing nickel and chromium metals $[9,10]$. The known cancer risk presented by nickel, chromium, and their compounds has been documented in the literature [11-13].

The nickel is one of the most common allergens and the most potent sensitizer of all metals and have been described as -ontact allergens" [14]. It has been shown that those patients who are allergic to nickel will react to certain nickel chromium dental alloys [14, 15].

In pediatric dentistry, the stainless steel crowns and space maintainers are widely used. These are made of base alloy mainly containing nickel and chromium as the main constituents. Since the oral environment is particularly ideal for the biodegradation of metals because of its ionic, thermal, microbiological, and enzymatic properties, the level of patient exposure to the corrosion products of these alloys could be assumed, if not assured [16].

The aim of this study is to investigate and compare the salivary level of nickel and chromium in the children having lingual arch space maintainer appliances versus those having stainless steel crowns.

\section{Materials and Methods}

Thirty four Patients were selected and allocated into two groups group I consisted of 17 patients who were in need of lingual arch space maintainer appliances, while group II consisted of 17 patients who were in need of two stainless steel crowns. All patients were selected after fulfilling the inclusion criteria as follow: 


\section{International Journal of Science and Research (IJSR)

For both groups I and II:

1. Age range from 6-8 years.

2. No amalgam fillings or metal restorations.

3. No brackets, headgear or extraoral appliances.

4. Free of any systemic disease or syndrome.

5. Cooperative child according to Frankl rating scale $(++)$ or $(+)$.

For group I:

1. Eruption of mandibular permanent first molar and incisors.

2. Unilateral or bilateral premature loss of mandibular primary molars or canines.

\section{For group II:}

1. Second primary molars with extensive and/or multiple carious lesions.

2. Second primary molars after pulp therapy.

The children's parents or guardian were asked to sign an informed consent after explanation of the purpose of the study to the parents, medical and dental histories were taken. Children having any dental condition requiring treatment were managed by using non metallic restorations for ethical consideration.

For both groups the samples of saliva were collected at four stages:

T1: before appliance or SSC cementation.

T2:1month after appliance or SSC cementation.

T3: 3 months after appliance or SSC cementation.

T4: 6 months after appliance or SSC cementation.

The parents were instructed that the last meal should be at least 3 hours before the appointment at the four stages. The salivary sample was taken after rinsing the mouth with distilled water. The sample was collected into a plastic tube without salivary stimulation then each sample had been taken a code number of each patient and was stored at ice box below $25 \mathrm{C}$.

The analysis was initially performed with 2380 Perkin Elmer atomic absorption spectrophotometer; which is a technique based on the unique spectrum of each element. The metal content of all samples will be analyzed three times, and the average will be reported[4].

\section{Statistical Analysis}

Data were collected and entered to the computer using Statistical Package for Social Science (SPSS) program for statistical analysis (version 20)[17]. Data were entered as numerical. Kolmogorov-Smirnov test was used to test normality of the distribution of variables. The data was normally distributed but non-parametric statistics were adopted even when KS test was not significant due to small sample size and also the non-parametric statistics is more robust. Comparison using Mann-Whitney $U$ test was used to test two independent samples. Comparison of related samples was carried out by Friedman Nonparametric Tests. Pairwise Post Hoc tests for Friedman in Nonparametric Tests were carried out using DunnBonferroni test[18].Box and Whiskers graphs were used to represent the data.

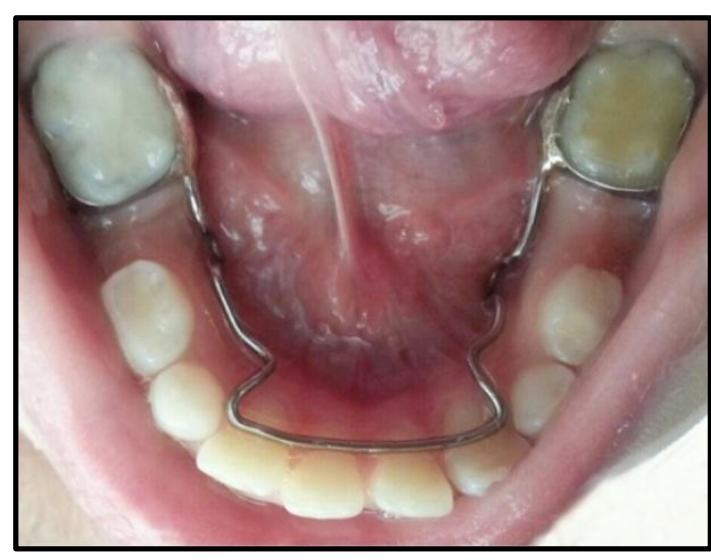

Figure 1: Lingual arch space maintainer after cementation.

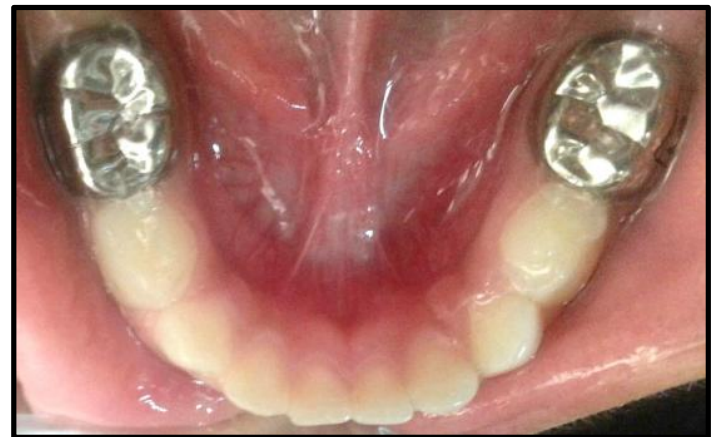

Figure 2: Stainless steel crowns on the second primary molars.

\section{Result}

No statistical significant difference found between the two studied groups regarding the concentration of nickel or chromium before the appliance or stainless steel crowns cementation $(\mathrm{p}=0.375, \quad 0.131)$ for nickel and chromium respectively. There was a statistical significant difference found between two studied groups regarding the concentration of nickel one month and three months after cementation $(p=0.001,0.005)$ respectively but after six months no significant difference found between the two groups $(p=0.074)$. The chromium concentration during three stages after cementation show a statistical significant increase in group I when compared to group II $(p=0.001)$. The amount of released nickel and chromium were significantly higher in group I when compared to group II. The maximum increase of the concentration of nickel and chromium elements in both groups were seen after one month there after the concentration were gradually decreased till reach the baseline levels. The result of the present study shows a significant increase in the salivary levels of nickel and chromium elements in both groups after cementation of space maintainer appliances or SSC $(p=0.001)$. Also there was a statistical significant difference found in both groups concerning the concentration or nickel and chromium during the stages of treatment period $(\mathrm{p}=0.001)$. 


\section{International Journal of Science and Research (IJSR) \\ ISSN (Online): 2319-7064}

Index Copernicus Value (2013): 6.14 | Impact Factor (2014): 5.611

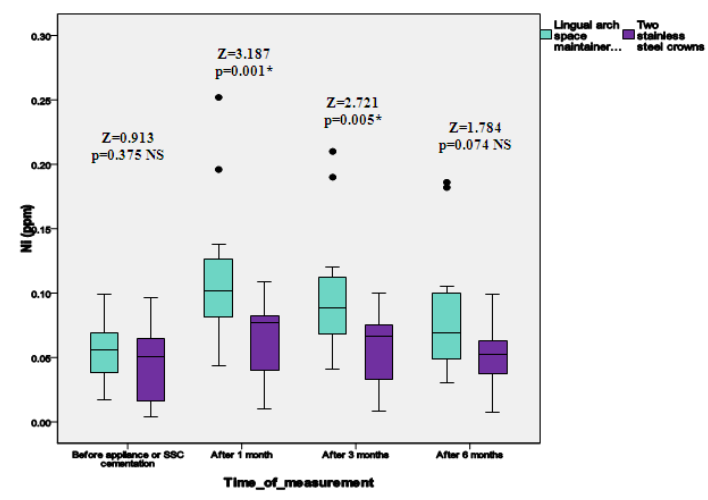

Figure 3: Box and whisker graph of a comparison between two studied groups regarding the concentrations of nickel (ppm) during all stages of treatment.

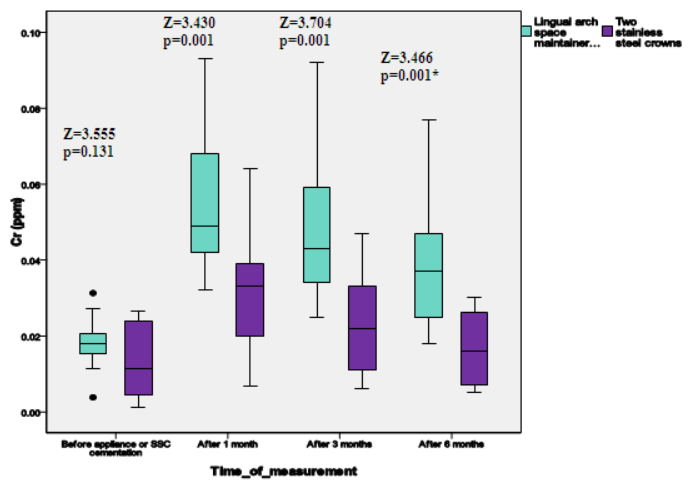

Figure 4: Box and whisker graph of a comparison between two studied groups regarding the concentrations of chromium (ppm) during all stages of treatment.

\section{Discussion}

In the present study nickel and chromium were chosen to be analyzed due to the level of environmental danger posed by their pollution of the natural ecosystem, thus the study was conducted in vivo to investigate whether the use of space maintainer appliances or stainless steel crowns is a potentially significant source of exposure to toxic metals.

Salivary samples were preferred to obtain from patients in order to analyze the release in the dynamic oral cavity environment. Also artificial salivary solutions are not commonly used in long-term studies based on their precipitation disadvantage[19].

Saliva has a dynamic composition that may be affected by many physiologic variables such as health conditions and medications. Thus children who did not have any health problem were allocated[20]. Also variables such as diet, salivary $\mathrm{pH}$ and salivary flow rate may affect the nature of collected saliva so it was preferred to collect the sample at least 3 hours following the last meal and after rinsing with distilled water to standardize flow rate and to avoid an influence on nickel or chromium contents by diet. This was in agreement with Nyvad and Fejerskov (1994)[21] who reported that nickel or chromium release into the saliva is more likely to take place shortly after a meal due to the sharp fall in $\mathrm{pH}$ within minutes which reduce the resistance of dental alloys to corrosion. Salivary $\mathrm{PH}$ general not returned to the normal until $30-60$ minutes after intake.

The protocol of stimulated saliva collection by chewing on a piece of paraffin wax or gum restricts the collection of saliva to that secreted almost directly from the gland. This effect resulting in the lack of saliva wetting of the oral cavity and limiting the exposure of appliances to salivary flow, thus possibly inducing a false negative result[22]. Therefore, in the present study the salivary samples were taken from the patient without stimulation in order to measure the actual concentration of nickel and chromium in flowing saliva.

Patients having oral metallic appliances or amalgam restorations were excluded from the study because of the possible presence of nickel, chromium and their compounds, which may affect their salivary levels[4]. Also for the sake of standardization, the same supplies to all patients in the same group was used as in group I (bands) and group II (SSC) were selected from Ormco Corporation Glendora, and 3M ESPE" companies respectively.

The spectrophotometric determinations of nickel and chromium were carried out using Perkin Elmer 2380 atomic absorption spectrophotometer. This technique was used to analyze nickel and chromium release because other analysis techniques like calirometric analysis and ultraviolet spectrophotometry were not as accurate as atomic absorption spectrophotometer to measure the nickel and chromium levels below 1 ppm[3,10,19,23].

Lingual arch space maintainer and SSC are generally used intraorally for extended time and for evaluating the state of released elements it's important to carry out the process during different stages of the treatment period, so there was a necessity for long-term research of nickel and chromium release. Limiting the study to one stage may result in ignorance of metals release variation during different stages.

Eliades et al (2003)[22]studied the levels of nickel, chromium and iron in orthodontic patients and no significant difference was detected when compared to the levels of these elements in control groups. However since their study was limited to the samples collected before treatment and one stage after that, they postulated that the concentration of these elements may change during different stages. Based on this assumption in the present study the salivary nickel and chromium were evaluated in four stages during a six months period of treatment.

In the current study, there was a significant difference between the two studied groups concerning the release of nickel and chromium in all stages after cementation except for the concentration of nickel after six month as there was no significant difference. The amount of released nickel and chromium were generally higher in the group I compared to group II. This may be because that the release of nickel and chromium are directly proportional to the amount of metallic surface area exposed to the oral environment so that the available content of nickel and chromium were increased for corrosion this is in agreement with Bhaskar and Reddy (2010)[16] who reported that the release of nickel and chromium was directly proportional to the number of space maintainers used. 


\section{International Journal of Science and Research (IJSR) \\ ISSN (Online): 2319-7064 \\ Index Copernicus Value (2013): 6.14 | Impact Factor (2014): 5.611}

The maximum release of nickel and chromium were seen within the first month, and thereafter the release of nickel and chromium was gradually decreased. This finding is in agreement with those of Kerousuo et al (1997),[23]Ağaoğlu et al.(2001) [19] and Petoumenou et al (2009) [24], who reported an increase in salivary nickel and chromium concentration 1 month after appliance insertion. Also consistent with the finding of Yassaei et al (2013) [4] although their first stage of evaluation was after 20 days of the appliance insertion. The possible explanation would be if nickel and chromium present on the surface of the space maintainers or SSC may quickly corrode during the first month, then the rate of release drops off as the surface nickel and chromium is depleted [16].

All values found in the present study were much below the average dietary intake of $200-300 \mathrm{mg} / \mathrm{d}$ and $50-200 \mathrm{mg} / \mathrm{d}$ for nickel and chromium respectively and these amounts are not capable to cause toxicity.

\section{Conclusion}

It can be concluded that the amount of salivary nickel and chromium released after lingual arch space maintainer appliances were more than those after SSC. Also the maximum amounts of released nickel and chromium were much lower than the dietary intake and were not capable of causing any toxicity.

\section{References}

[1] P.B. Tchounwou, C.G. Yedjou, A.K. Patlolla, D.J. Sutton. "Heavy Metals Toxicity and the Environment," NIH Public Access, 101,pp. 133-164, 2012.

[2] M.R. Grimsdottir, N.R. Gjerdet, A. HenstenPettersen,"Composition and in vitro corrosion of orthodontic appliances," Am J Orthod Dento facial Orthop, 101, pp. 525-532, 1992.

[3] R.D. Barrett, S.E. Bishara, J.K. Quinn,"Biodegradation of orthodontic appliances: part I. Biodegradation of nickel and chromium in vitro," Am J Orthod Dento facial Orthop, 103, pp. 8-14, 1993.

[4] S. Yassaei, S. Dadfarina, H. Ahdian, F. Moradi, "Nickel and Chromium levels in saliva of patients with fixed orthodontics," Orthodontics(Chic),14, pp. e76-81, 2013.

[5] H. Kerousou, G. Moe, E. Kleven, "In vitro release of nickel and chromium from different types of stimulated orthodontic appliances," Angle Orthod,65, pp. 111-116, 1999.

[6] G. Schuster, R. Reichle, R.R. Bauer, P.M. Schopf, "Allergy induced by orthodontic alloy:Incidence and impact on treatment.Result on survey in private orthodontic offices in the Fedral State of Hesse,Germany," J Orofac Orthop,65, pp. 48-59, 2004.

[7] J. Noble, S.I. Ahing, N.E. Karaiaskos, W.A. Wiltshir," Nickel allergy and orthodontics:A review and report of two cases," Br Dent J,204, pp. 297-300, 2008.

[8] A. Patel, D.J. Burden, J. Sandler, "Medical disorders and orthodontics," J Orthod,36, pp. 1-21, 2009.

[9] Workshop: biocompatibility of metals in dentistry, "National Institute of Dental Research" J Am Dent Assoc, 109, pp. 469-471, 1984.

[10] S.E. Bishara, R.D. Barrett, M.I. Selim,"Biodegradation of orthodontic appliances - Part II Changes in the blood level of Nickel," Am J Orthod Dento facial Orthop,103, pp. 115-119, 1993.
[11]D.G. Barceloux,"Nickel," J ClinToxicol,37, pp. 239258, 1999.

[12] T. Norseth,"The carcinogenicity of chromium," Environ Health Perspect,40, pp. 121-130, 1981.

[13]R. Khilifi, P. Olmedo, F. Gil, M. Feki-Tounsi, A. Chakroun, A. Rebai, et al, "Blood nickel and chromium levels in association with smoking and occupational exposure among head and neck cancer patient," Environ Sci Pollut Res Int,20, pp. 8282-8294, 2013.

[14] J.P. Fernandez, C. Veron, H.F. Hildebrand, P. Martin,"Nickel allergy to dental prosthesis," Contact Dermatitis, 14, p. 312, 1986.

[15] W.H. Feasby, E.R. Ecclestone, R.M. Grainger,"Nickel sensitivity in pediatric dental patients,"Pediatr Dent,10, pp. 127-129, 1988.

[16] V. Bhaskar, S. Reddy, "Biodegradation of nickel and chromium from space maintainers," J Indian Soc Pedod Prevent Dent,28: pp. 6-12, 2010.

[17] SPSS Inc.Released2008.SPSS Statistics for Windows, Version 17.0. Chicago: SPSS Inc.

[18] O.J. Dunn,"Multiple Comparisons Using Rank Sums. Technometrics," 6,pp. 241-52, 1964.

[19] G. Ağaoğlu, T. Arun, B. Izgi, A. Yarat,"Nickel and chromium levels in the saliva and serum of patients with fixed orthodontic appliances," Angle Orthodontist, 71,pp. 375-379, 2001.

[20] C.G. Crossner,"Salivary flow rate in children and adolescents,"Swed Dent J, 8, pp. 271-276, 1984.

[21]B. Nyvad, O. Fejerskov.Development, structure and $\mathrm{pH}$ of dentalplaque. In: A. Thylstrup, O. Fejerskov (eds). Textbook of clinical cariology. 2nd ed, Copenhagen: Munksgaard, 1994.

[22] T. Eliades, C. Trapalis, G. Eliades, E. Katsavrias, "Salivary metal levels of patients: a novel methodological and analytical approach,"Eur J Orthod, 25,pp. 103-106, 2003.

[23] H. Kerosuo, G. Moe, A. Hensten-Pettersen,"Salivary nickel and chromium in subjects with different types of fixed orthodontic appliances," Am J Orthod Dento facial Orthop, 111, pp. 595-598, $1997 .$.

[24]E. Petoumenou, M. Arndt, L. Kilieg,"Nickel concentration in the saliva of patient with nickeltitanium orthodontic appliances,Am J Orthod Dento facial Orthop, 135, pp. 59-65, 2009.

\section{Author Profile}

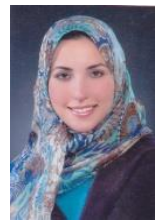

Tasneem Tarek Mahmoud Gowayed, received the B.D.S. In Dental and Oral Surgery from Alexandria University, Faculty of Dentistry 2007. During 2007 till now, she practiced in Ministry of Health. She started preparation of master degree in Pediatric Dentistry and Dental Public Health at Faculty of Dentistry, Alexandria University since 2012. 